\title{
Adsorption of Enrofloxacin on montmorillonite: Two-dimensional correlation ATR/FTIR spectroscopy study
}

\author{
Wei Yan ${ }^{\mathrm{a}}$, Jianfeng Zhang ${ }^{\mathrm{b}}$, Chuanyong Jing ${ }^{\mathrm{a}, *}$ \\ a State Key Laboratory of Environmental Chemistry and Ecotoxicology, Research Center for Eco-Environmental Sciences, Chinese Academy of Sciences, P.O. Box 2871, \\ Beijing 100085, China \\ ${ }^{\mathrm{b}}$ School of Environmental and Municipal Engineering, Xi'an University of Architecture and Technology, Xi'an 710055, China
}

\section{A R T I C L E I N F O}

\section{Article history:}

Received 7 July 2012

Accepted 17 September 2012

Available online 26 September 2012

\section{Keywords:}

Enrofloxacin (ENR)

2D-COS

Sorption

Clay mineral

ATR-FTIR

\begin{abstract}
A B S T R A C T
Adsorption of Enrofloxacin (ENR) on minerals dominates the fate and transport of ENR in the environment. In this study, the sorption process of ENR on montmorillonite and the impact of dissolved organic matters (DOMs) on ENR-montmorillonite interactions were investigated using in situ ATR-FTIR spectroscopy and two-dimensional correlation analysis (2D-COS). Negative peaks were observed in the $3400-2900 \mathrm{~cm}^{-1}$ region due to the loss of hydrated protons at montmorillonite surfaces. The primary characteristic peaks of adsorbed ENR molecules were resolved in the $1800-1100 \mathrm{~cm}^{-1}$ range. The results of $2 \mathrm{D}-\mathrm{COS}$ suggested the sorption process was initiated by the interaction of hydrated protons on montmorillonite surfaces with diverse moieties of ENR molecules depending on $\mathrm{pH}$. The sorption mechanism of ENR was mainly cation exchange at acidic condition, charge neutralization at neutral condition, and proton transfer at alkaline condition. DOM could interact with piperazinyl amine groups of dissolved ENR, which changed the interaction sequence of ENR molecule with montmorillonite surfaces. Electrostatic interaction was the predominant driving force for the interaction between DOM and dissolved ENR. H-donor-acceptor interaction and $\pi-\pi$ interaction may also be responsible to this interaction. Insights gained from this study improve our understandings on sorption mechanism of ENR and similar ionic organic pollutants in soil systems.
\end{abstract}

(C) 2012 Elsevier Inc. All rights reserved.

\section{Introduction}

Enrofloxacin (ENR) is a class of fluoroquinolone (FQ) antibiotics extensively used in veterinary pharmaceuticals $[1,2]$. Continuous ENR discharge to the environment results in the pseudo-persistent occurrence of ENR at ng L ${ }^{-1}$ to low $\mu \mathrm{g} \mathrm{L}^{-1}$ levels [3-5]. Prolonged exposure to ENR can promote antibiotic-resistance of bacteria and ultimately pose potential threats to ecological and human health [6-8]. Therefore, the need to predict its environmental risks motivates the research in the environmental behaviors of ENR.

Clay minerals are widely considered as an active component of soils for the adsorption of polar xenobiotics [9]. Sorption of ENR and ENR-like FQ compounds by clay minerals such as montmorillonite [2,10-12], kaolinite [10], metal (hydrous) oxides [6,13-15], and silica [15] has been widely investigated. Several interaction mechanisms between ENR and clay minerals have been proposed including electrostatic attraction [16], cation bridging [2,15], cation exchange [17], and surface complexation or ligand exchange [6,13]. Our previous study has demonstrated that multiple interactions simultaneously occurred [18]: cation exchange is the

\footnotetext{
* Corresponding author. Fax: +86 1062849523.

E-mail address: cyjing@rcees.ac.cn (C. Jing).
}

dominant interaction between the protonated piperazinyl amine groups of ENR and the exchangeable cations on mineral surface; a small fraction of ENR molecules are adsorbed due to ligand exchange between carboxyl groups of ENR and hydroxyl groups on the mineral edge surface. These studies, however, under appreciate the polar characteristics of $\mathrm{H}_{2} \mathrm{O}$ in sorbate-water and sorbentwater interactions, which may hinder the comprehensive understanding of the dynamic sorption process of polar organic pollutants.

Dissolved organic matter (DOM) plays an important role in the adsorption of ionizable organic compounds (IOCs) on clay minerals $[19,20]$. DOM can form complexes on clay minerals and subsequently change their surface properties $[21,22]$. The interactions among DOM, geosorbents, and IOCs are complicated because of the heterogeneity of DOM, diverse surface structures of clay minerals, and different molecular configurations of IOCs. The complexity of IOCs behaviors in this three-phase system should be taken into consideration to accurately simulate the interfacial processes in the environment.

Two-dimensional correlation spectroscopy (2D-COS) has been successfully applied to investigate the dynamics of adsorption, diffusion, and biological processes [23,24]. Based on the dynamic fluctuations of spectral intensity, 2D-COS is especially suitable in 
the study of external perturbations such as the change in $\mathrm{pH}$ and concentration using in situ flow-cell attenuated total reflectance Fourier transform infrared (ATR-FTIR) analysis. Two major advantages of 2D-COS are remarkable: One is its simplification in resolving overlapped peaks and enhancing spectral resolution. More importantly, 2D-COS can probe the specific sequence of spectral intensity changes corresponding to external perturbations [25]. To the best of our knowledge, no study has documented using 2D-COS to investigate the mineral-aqueous solution interfacial behaviors of organic contaminants in the presence of DOM.

The objective of this work was to investigate the impact of DOM on the ENR sorption on montmorillonite. The ATR-FTIR and 2DCOS analysis were employed to gain important insights during the ENR adsorption in the presence of humic acid (HA) and fulvic acid (FA) under various $\mathrm{pH}$ conditions.

\section{Materials and methods}

\subsection{Materials}

Montmorillonite (SWy-2) was obtained from the Source Clays Repository of the Clay Minerals Society (West Lafayette, Indiana, USA). The surface area of SWy-2 is ca. $32 \mathrm{~m}^{2} \mathrm{~g}^{-1}$ and its cation exchange capacity is $76 \mathrm{cmol}_{\mathrm{C}} \mathrm{kg}^{-1}$ [26]. The fraction with less than $2-\mu \mathrm{m}$ size was separated by wet sedimentation and repeatedly washed with $0.1 \mathrm{M} \mathrm{KCl}$ solution. Then, the saturated clay sample was washed with deionized water to remove the excess electrolyte until the absence of chloride. The pretreated clay was then lyophilized and ready for use.

ENR (purity $\geqslant 98 \%$, HPLC grade) was used as received from Fluka (Biochemica, distributed by Sigma-Aldrich, St. Louis. Missouri, USA). Suwannee River HA (catalog no. 2S101H) and Suwannee River FA (catalog no. 2S101F) were obtained from International Humic Substances Society (IHSS). HA solution was prepared by dissolving $100 \mathrm{mg}$ of HA in $100 \mathrm{~mL}$ Milli-Q water. The $\mathrm{pH}$ was adjusted to 10 with $\mathrm{NaOH}$, and the solution was then passed through a $0.45-\mu \mathrm{m}$ cellulose nitrate filter. Inorganic chemicals, including $\mathrm{KCl}, \mathrm{AgNO}_{3}, \mathrm{NaOH}$ ( $\geqslant 98 \%$ ) of analytical grade or higher, were purchased from Shanghai Chemical Reagent Co., Ltd. (Shanghai, China).

\subsection{FTIR measurements}

In situ flow cell ATR-FTIR measurements were performed using a Thermo-Nicolet Nexus 6700 FTIR spectrometer equipped with a liquid-nitrogen cooled MCT detector. The IR spectra were collected using a horizontal attenuated total reflectance (HATR) cell (PIKE Tech) with a $45^{\circ} \mathrm{ZnSe}$ ATR crystal. A total of 512 scans were recorded over $600-4000 \mathrm{~cm}^{-1}$ at a resolution of $4 \mathrm{~cm}^{-1}$ for each spectrum.

ATR-FTIR measurements of ENR sorption on clay were similar to a previous publication with minor modifications [6]. Briefly, a $500 \mu \mathrm{L}$ suspension containing $2 \mathrm{mg}$ of montmorillonite (K-SWy2) was evenly spread on the ZnSe crystal and air-dried overnight to form a uniform clay film. The flow cell with the coated film was washed with $0.01 \mathrm{M} \mathrm{KCl}$ solution using a LC pump (LC 10A, Shimadzu Corp.) at a flow rate of $0.6 \mathrm{~mL} \mathrm{~min}^{-1}$ for $40 \mathrm{~min}$ to flush out the uncoated particles and other impurities. The background IR spectrum was collected and saved. The electrolyte solution was then changed to a $10 \mathrm{mg} \mathrm{L}^{-1}$ ENR solution $(27.8 \mu \mathrm{M})$ at the same $\mathrm{pH}$ value as that of electrolyte solution. Spectra were recorded as a function of time until the sorption reached equilibrium. HA/FA sorption and its cosorption with ENR on montmorillonite were measured using the same process.

\section{3. $2 D-\operatorname{COS}$}

After essential smooth and baseline correction performed using the Omnic 8.0 software, FTIR spectra collected with an increment of $15 \mathrm{~min}$ during adsorption process were selected for 2D correlation analysis using the 2Dshige software (Shigeaki Morita, Kwansei-Gakuin University, 2004-2005). The sequential order of intensity change between band $v_{1}$ and $v_{2}$ could be obtained from the sign of synchronous correlation peak $\Phi\left(v_{1}, v_{2}\right)$ and asynchronous correlation peak $\Psi\left(v_{1}, v_{2}\right)$ under the well-established principles $[24,27]$. In brief, the change in the spectral intensity at $v_{1}$ band occurs prior to that at $v_{2}$ if $\Phi\left(v_{1}, v_{2}\right)$ and $\Psi\left(v_{1}, v_{2}\right)$ have the same sign, while the order is reversed if $\Phi\left(v_{1}, v_{2}\right)$ and $\Psi\left(v_{1}, v_{2}\right)$ have the opposite sign. The changes at $v_{1}$ and $v_{2}$ occur simultaneously if $\Psi\left(v_{1}, v_{2}\right)$ is zero.

\section{Results and discussion}

\subsection{FTIR analysis of ENR sorption}

The FTIR spectra of ENR on K-SWy-2 montmorillonite at pH 4.5 as a function of sorption time are present in Fig. 1a. The striking spectral changes mainly occurred at $3400-2900 \mathrm{~cm}^{-1}$ and $1800-$ $1100 \mathrm{~cm}^{-1}$ regions that were the focus in this study (Fig. 1b and c).

A negative peak at $3148 \mathrm{~cm}^{-1}$ was progressively increased in intensity as a function of sorption time (Fig. 1b), indicating that a molecule originally adsorbed on montmorillonite was gradually released. The originally adsorbed molecule was expected to be water because the polarity of water molecule makes it easy to be adsorbed on the charged clay mineral. The $\mathrm{OH}$ stretching of bulk water, however, is usually observed at $3294 \mathrm{~cm}^{-1}$ [28]. A discrepancy of $146 \mathrm{~cm}^{-1}$ of the $v(\mathrm{OH})$ band suggested that the structure and properties of interfacial water were significantly perturbed compared to those of bulk water.

Surface protonation effect may account for this perturbation. The montmorillonite contains negative structure charges on basal planes due to isomorphic cation substitutions. The negative charges can be compensated by protons $\left(\mathrm{H}_{\mathrm{aq}}^{+}\right)$and cations (e.g., $\mathrm{K}^{+}$) from the electrolyte near the basal planes, leading to an increased proton activity in the vicinal solution near the surfaces $\left(\mathrm{pH}_{\mathrm{vicinal}}<\mathrm{pH}_{\text {bulk }}\right)$. In this vicinal solution with strong acid, concentrated protons can be associated with its nearest-neighbor water molecules to form a hydrated hydrogen ion, $\mathrm{H}\left(\mathrm{H}_{2} \mathrm{O}\right)_{n}^{+}$, and then adsorbed on the negatively charged surface. In agreement with our observation, Stoyanov et al. found that the $v(\mathrm{OH})$ vibration of aqueous $\mathrm{H}\left(\mathrm{H}_{2} \mathrm{O}\right)_{6}^{+}$was centered at $3146 \mathrm{~cm}^{-1}$ [29]. Similar solvation complex of exchangeable cation, such as $\mathrm{Ca}\left(\mathrm{H}_{2} \mathrm{O}\right)_{6}^{2+}$, has also been reported to be immobilized at the clay mineral interlayer [30]. Therefore, the absorbance loss in $3148 \mathrm{~cm}^{-1}$ was due to the release of adsorbed $\mathrm{H}\left(\mathrm{H}_{2} \mathrm{O}\right)_{6}^{+}$.

The spectra in the region of $1800-1100 \mathrm{~cm}^{-1}$ (Fig. 1c) exhibited main characteristic peaks of adsorbed ENR molecule. The peak position and assignment are shown in Table 1. A successive increase in intensity upon ENR sorption was observed with the increase in sorption time. However, the spectroscopic method alone is not sensitive enough to reveal the dynamics of the sorption process.

\subsection{Two-dimensional correlation analysis}

ENR sorption on montmorillonite is complicated due to its structure properties (Fig. S1). Depending on the solution pH, ENR can exist as three dominant species, namely cationic ENR $\left(\mathrm{ENR}^{+}\right)$, zwitterionic ENR $\left(\mathrm{ENR}^{ \pm}\right)$, and anionic ENR $\left(\mathrm{ENR}^{-}\right)\left(\mathrm{p} K_{\mathrm{a} 1}=6.27\right.$, $\left.\mathrm{p} K_{\mathrm{a} 2}=8.30\right)$. The sorption of different ENR species may control by different mechanisms. In addition, montmorillonite contains two 

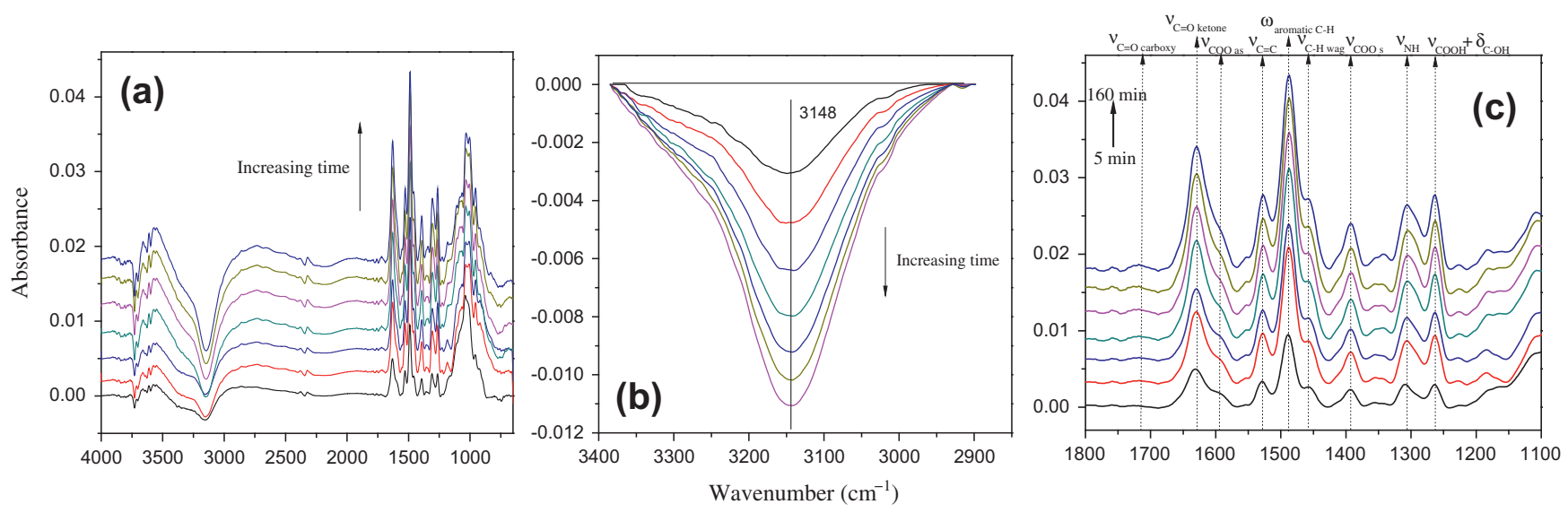

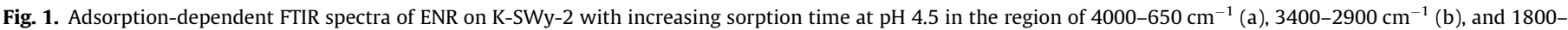
$1100 \mathrm{~cm}^{-1}(\mathrm{c})$.

Table 1

Vibrational frequencies $\left(\mathrm{cm}^{-1}\right)$ and assignments for adsorbed ENR on clay.

\begin{tabular}{ll}
\hline Position $\left(\mathrm{cm}^{-1}\right)$ & Assignment \\
\hline 1706 & Carboxylic acid $\mathrm{C}=\mathrm{O}$ stretch $\left(v_{\mathrm{C}=\mathrm{O} \text { carboxy }}\right)$ \\
1628 & Ketone $\mathrm{C}=\mathrm{O}$ stretch $\left(v_{\mathrm{C}=\mathrm{O} \text { ketone }}\right)$ \\
1584 & Carboxylate $\mathrm{COO}^{-}$antisymmetric stretch $\left(v_{\mathrm{COOas}}\right)$ \\
1528 & Aromatic $\mathrm{C}=\mathrm{C}$ stretch $\left(v_{\mathrm{C}=\mathrm{C}}\right)$ \\
1486 & Aromatic $\mathrm{C}-\mathrm{H}$ wag $\left(\omega_{\text {aromatic }} \mathrm{C}-\mathrm{H}\right)$ \\
1456 & $\mathrm{C}-\mathrm{H}$ wag $\left(\omega_{\mathrm{C}-\mathrm{H}}\right)$ \\
1394 & Carboxylate $\mathrm{COO}-$ symmetric stretch $\left(v_{\mathrm{COOs}}\right)$ \\
1302 & $-\mathrm{NH}^{+}$twisting $\left(\tau_{\mathrm{NH}}\right)$ \\
1264 & $\mathrm{C}-\mathrm{O}$ stretch $\left(v_{\mathrm{COOH}}\right)+\mathrm{C}-\mathrm{O}-\mathrm{H}$ deformation $\left(\delta_{\mathrm{C}-\mathrm{OH}}\right)$ \\
&
\end{tabular}

types of surfaces. The basal planes carry permanent negative charge, and the edge surfaces contain $\mathrm{pH}$-dependent charges with the amount of about $10 \%$ of the total charge. Both surfaces can interact with ENR, increasing the difficulty in the sorption process analysis [31].

To further discern the sorption sequence of each ENR functional groups during sorption at different $\mathrm{pH}, 2 \mathrm{D}-\mathrm{COS}$ was employed and the results are shown in Fig. 2 and Table 2. Correlation peaks are indicated by the contour map where blue (red) regions were defined as negative (positive) correlation intensities. Because carboxyl group and piperazinyl amine group of ENR molecule are the main functional groups involved in sorption [18], these two function groups with vibrational peaks in the range of 1400$1200 \mathrm{~cm}^{-1}$ were investigated.

Two-dimensional synchronous spectra (Fig. 2a, c, e) could reflect simultaneous change between the correlated peaks. For all investigated $\mathrm{pHs}$, three prominent auto-peaks on the diagonal were observed at 1394,1302 , and $1264 \mathrm{~cm}^{-1}$ in synchronous spectra, suggesting that the spectral intensities in these peaks have distinctly changed during the adsorption process. Three positive cross peaks off the diagonal at 1302/1394, 1264/1394, and 1264/ $1302 \mathrm{~cm}^{-1}$ were also exhibited in the synchronous spectra. The positive sign of the cross peaks indicated that the peaks at 1264 , 1302 , and $1394 \mathrm{~cm}^{-1}$ were of the same origin and resulted in the same responses of spectral intensities to the adsorption perturbation. These cross peaks were derived from vibrations of adsorbed ENR (Table 1), and the adsorption capacity was increased with the increase in sorption time.

Two-dimensional asynchronous spectra could identify the specific order in surface interactions taking place under external perturbations. In this study, the sequences of vibrational response toward the perturbation of surface sorption were different at $\mathrm{pH}$ 4.5, 7, and 9 (Fig. 2b, d, f). At pH 4.5 (Fig. 2b), a strong positive cross peak at $1302 / 1264 \mathrm{~cm}^{-1}$ and a weak negative cross peak at 1394/ $1302 \mathrm{~cm}^{-1}$ were observed. The asynchronous correlation analysis based on the Noda's rule [24] led to the sequence of the spectral change (" $\rightarrow$ " means prior to): $1302 \rightarrow 1264 \mathrm{~cm}^{-1}, 1302 \rightarrow$ $1394 \mathrm{~cm}^{-1}$. Similarly, the sequence of the spectral change at $\mathrm{pH} 7$ (Fig. 2d) was $1264 \rightarrow 1302 \mathrm{~cm}^{-1}, 1264 \rightarrow 1394 \mathrm{~cm}^{-1}, 1394 \rightarrow$ $1302 \mathrm{~cm}^{-1}$. At pH 9 (Fig. 2f), the cross peak at $1302 / 1264 \mathrm{~cm}^{-1}$ was too weak to be clearly resolved. Instead, strong negative cross peaks at $1394 / 1302 \mathrm{~cm}^{-1}$ and $1394 / 1264 \mathrm{~cm}^{-1}$ were observed and the sequence of the spectral change was $1302 \rightarrow 1394 \mathrm{~cm}^{-1}$, $1264 \rightarrow 1394 \mathrm{~cm}^{-1}$. The results of 2D-COS are summarized in Table 2 . The spectral analysis resulted in a $\mathrm{pH}$-dependent ENR sorption process on clay surfaces (Fig. 3). The dynamic processes at $\mathrm{pH} 4.5$, 7 , and 9 are discussed in detail as follows.

At $\mathrm{pH} 4.5$, clusters of hydrated protons (e.g., $\mathrm{H}\left(\mathrm{H}_{2} \mathrm{O}\right)_{6}^{+}$) were attracted to the negatively charged clay surfaces and the electrical double layer (EDL) was formed. Because the siloxane group $\left(\mathrm{Si}_{2}-\mathrm{O}\right)$ at the basal surface of clay is chemically inert with an intrinsic protonation constant at -16.9 [32], the specifically adsorbing ions are unable to exist at the basal surface. Thus, the classic Basic Stern (BS) model can describe the adsorption behaviors in the EDL in our study [33]. In addition, the $\zeta$ potential of montmorillonite is negative $(-30$ to $-50 \mathrm{mV}$ ) within a broad $\mathrm{pH}$ domain from 2 to 12 [34]. At pH 4.5 with the ionic strength of $0.01 \mathrm{M} \mathrm{KCl}$, the $\zeta$ potential of montmorillonite in this study was $-35.6 \mathrm{mV}$ (Fig. S2), indicating that the negative surface charge cannot be totally neutralized by the adsorbed counter ions $\left(\mathrm{H}^{+}, \mathrm{K}^{+}\right)$, even at low $\mathrm{pH}$. Meanwhile, 98.3\% ENR was in cationic form due to the protonation of piperazinyl amine group at $\mathrm{pH} 4.5$ (Fig. S1). This positive group was initially attracted to the solution side near the head end of the EDL by electrostatic forces, resulting in a subsequent cation exchange with the adsorbed $\left.\mathrm{H}_{(} \mathrm{H}_{2} \mathrm{O}\right)_{6}^{+}$. Moreover, the edge surface of phyllosilicate contains aluminum and silica sites with broken bonds [35]. These sites could interact with ENR to form surface complexes by ligand exchange. However, the contribution of ligand exchange may be negligible at $\mathrm{pH} 4.5$ because only less than $2 \%$ of carboxyl groups of ENR are in deprotonated form. Therefore, the sequence for the ENR sorption on the montmorillonite surface should be $-\mathrm{NH}^{+} \rightarrow-\mathrm{COOH}$. The possible ENR sorption processes at $\mathrm{pH} 4.5$ can be summarized as the following equation.

On basal planes,

Cation exchange $\equiv \mathrm{XH}\left(\mathrm{H}_{2} \mathrm{O}\right)_{n}+\mathrm{ENR}^{+} \leftrightarrow \equiv \mathrm{XENR}+\mathrm{H}\left(\mathrm{H}_{2} \mathrm{O}\right)_{n}^{+}$

where $\equiv \mathrm{X}^{-}$represents the structure charge sites.

At $\mathrm{pH} 7, \mathrm{ENR}^{ \pm}$became predominant and the negative $\zeta$ potential of montmorillonite surface was increased to $-41.3 \mathrm{mV}$ (Fig. S2). 


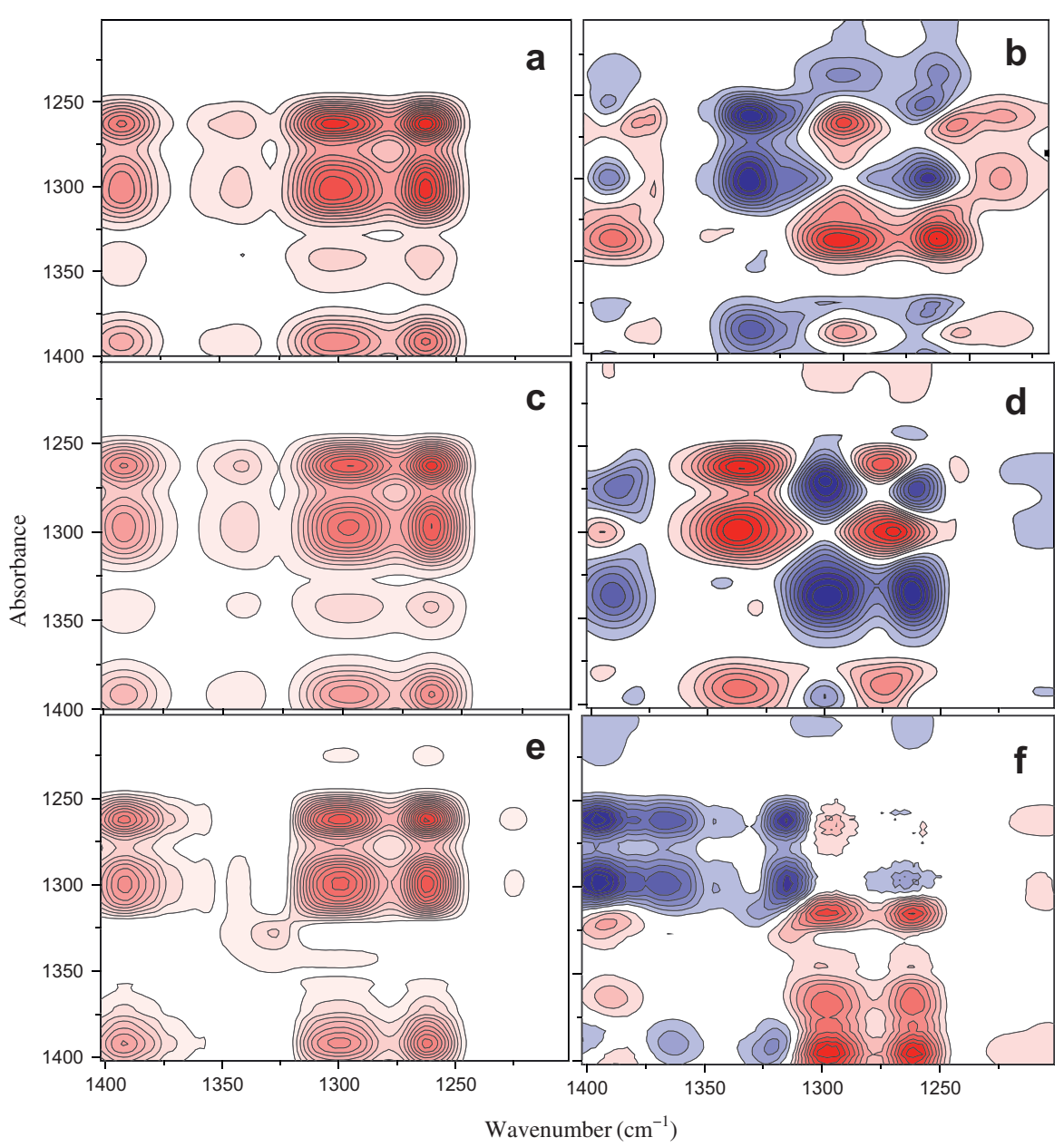

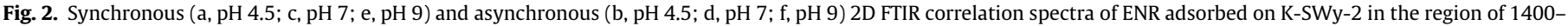
$1200 \mathrm{~cm}^{-1}$.

During the ENR ${ }^{ \pm}$adsorption due to electrostatic forces, some ENR ${ }^{ \pm}$ may change their molecular direction toward the surface because of increased repulsive forces (toward $\mathrm{NH}^{+}$) and attractive forces (toward $\mathrm{COO}^{-}$) of hydrated protons on the surface. Subsequently, $\mathrm{ENR}^{ \pm}$could enter the Stern layer by charge neutralization between deprotonated carboxyl groups of ENR and hydrated protons. This sorption process may dissociate $\mathrm{H}\left(\mathrm{H}_{2} \mathrm{O}\right)_{n}^{+}$and release water molecules, where the value of $n$ depends on $\mathrm{pH}_{\text {vicinal }}$ [29]. Thus, the sequence for the ENR sorption on the montmorillonite surface at $\mathrm{pH}$ 7 was $-\mathrm{COOH} \rightarrow-\mathrm{NH}^{+}$.

In addition, ligand exchange could occur between hydroxyl groups on the edge surface of montmorillonite and ENR $\mathrm{COO}^{-}$ groups. The possible ENR sorption process at $\mathrm{pH} 7$ can be summarized as follows.

On basal planes,

$$
\begin{aligned}
& \text { Neutralization } \mathrm{ENR}^{ \pm}+\mathrm{H}\left(\mathrm{H}_{2} \mathrm{O}\right)_{n}^{+} \leftrightarrow \mathrm{HENR}^{+}+n \mathrm{H}_{2} \mathrm{O} \text { (primary) } \\
& \begin{aligned}
\text { Cation exchange } & \equiv \mathrm{XH}\left(\mathrm{H}_{2} \mathrm{O}\right)_{n}+\mathrm{ENR}^{ \pm} \leftrightarrow \\
& \equiv \mathrm{XENR}^{-}+\mathrm{H}_{(}\left(\mathrm{H}_{2} \mathrm{O}\right)_{n}^{+}(\text {secondary })
\end{aligned}
\end{aligned}
$$

At edge surfaces,

Ligand exchange $\equiv \mathrm{Si}($ or $\mathrm{Al})-\mathrm{OH}+\mathrm{ENR}^{ \pm} \leftrightarrow$

$$
\equiv \mathrm{Si}(\text { or } \mathrm{Al})-\mathrm{ENR}^{+}+\mathrm{OH}^{-}
$$

At pH 9, montmorillonite surfaces contained a stronger negative $\zeta$ potential (42.2 mV, Fig. S2) and adsorbed less hydrated protons compared to that at $\mathrm{pH}$ 7. Meanwhile, about $38.6 \% \mathrm{ENR}^{ \pm}$and
61.2\% $\mathrm{ENR}^{-}$existed in bulk solution (Fig. S1). The decreased amount of protonated piperazinyl amine group led to a weak ENR sorption at alkaline condition. The sequence for the ENR sorption at $\mathrm{pH} 9$ was $-\mathrm{NH}^{+} \rightarrow-\mathrm{COO}^{-}$. The presence of a negative peak at around $3280 \mathrm{~cm}^{-1}$ (Fig. 4) may be explained by the following two reasons: (a) proton transfer occurred between piperazinyl amine group of $\mathrm{ENR}^{-}$and hydrated proton which released adsorbed water molecules; and (b) neutralization occurred between deprotonated carboxyl group of ENR ${ }^{ \pm}$and hydrated proton. The 2D-COS analysis favored the former interpretation. The possible ENR sorption process at $\mathrm{pH} 9$ can be summarized as follows.

On basal planes,

Proton transfer $\mathrm{ENR}^{-}+\mathrm{H}\left(\mathrm{H}_{2} \mathrm{O}\right)_{n}^{+} \leftrightarrow \mathrm{ENR}^{ \pm}+\mathrm{nH}_{2} \mathrm{O}$ (primary)

Cation exchange $\equiv \mathrm{XH}\left(\mathrm{H}_{2} \mathrm{O}\right)_{n}+\mathrm{ENR}^{ \pm} \leftrightarrow$

$$
\equiv \mathrm{XENR}^{-}+\mathrm{H}\left(\mathrm{H}_{2} \mathrm{O}\right)_{n}^{+} \text {(secondary) }
$$

At edge surfaces,

$$
\begin{aligned}
\text { Ligand exchange } & \equiv \mathrm{Si}(\text { or } \mathrm{Al})-\mathrm{OH}+\mathrm{ENR}^{-}\left(\text {or } \mathrm{ENR}^{ \pm}\right) \leftrightarrow \\
& \equiv \mathrm{Si}(\text { or } \mathrm{Al})-\mathrm{ENR}^{-}\left(\text {or } \equiv \mathrm{Al}-\mathrm{ENR}^{ \pm}\right)+\mathrm{OH}^{-}
\end{aligned}
$$

The proposed ENR sorption process at different $\mathrm{pH}$ was supported by 1D FTIR spectra in Fig. 4. With the increase in $\mathrm{pH}$, the number of " $\mathrm{n}$ " in $\mathrm{H}\left(\mathrm{H}_{2} \mathrm{O}\right)_{n}^{+}$changes, resulting in the shift of $v(\mathrm{OH})$ band of $\mathrm{H}\left(\mathrm{H}_{2} \mathrm{O}\right)_{n}^{+}$from $3146 \mathrm{~cm}^{-1}$ to $3166 \mathrm{~cm}^{-1}$. In addition, a distinct shoulder exhibited at around $3280 \mathrm{~cm}^{-1}$, which was probably due to the stretch of H-bonding of adsorbed water [36]. The con- 
Table 2

Results of 2D-COS on the sign of each cross peak in synchronous and asynchronous spectra.

\begin{tabular}{|c|c|c|c|c|c|c|c|c|c|}
\hline \multirow[t]{2}{*}{$\mathrm{pH}$} & & \multicolumn{3}{|c|}{ Signs of synchronous cross peaks $(\Phi)$} & \multicolumn{3}{|c|}{ Signs of asynchronous cross peaks ( $\Psi$ ) } & \multirow[t]{2}{*}{ The sequences of spectral change } & \multirow[t]{2}{*}{ Main reaction } \\
\hline & & 1394 & 1302 & 1264 & 1394 & 1302 & 1264 & & \\
\hline \multirow[t]{3}{*}{4.5} & 1394 & + & + & + & & - & & $-\mathrm{NH}^{+} \rightarrow \mathrm{COOH} ;-\mathrm{NH}^{+} \rightarrow \mathrm{COO}^{-}$ & Cation exchange \\
\hline & 1302 & + & + & + & + & & + & & \\
\hline & 1264 & + & + & + & & - & & & \\
\hline \multirow[t]{3}{*}{7.0} & 1394 & + & + & + & & + & - & $\mathrm{COOH} \rightarrow \mathrm{COO}^{-} ; \mathrm{COO}^{-} \rightarrow-\mathrm{NH}^{+} ; \mathrm{COOH} \rightarrow-\mathrm{NH}^{+}$ & Charge neutralization \\
\hline & 1302 & + & + & + & - & & - & & \\
\hline & 1264 & + & + & + & + & + & & & \\
\hline \multirow[t]{3}{*}{9.0} & 1394 & + & + & + & & - & - & $-\mathrm{NH}^{+} \rightarrow \mathrm{COO}^{-} ; \mathrm{COOH} \rightarrow \mathrm{COO}^{-}$ & Proton transfer \\
\hline & 1302 & + & + & + & + & & & & \\
\hline & 1264 & + & + & + & + & & & & \\
\hline
\end{tabular}

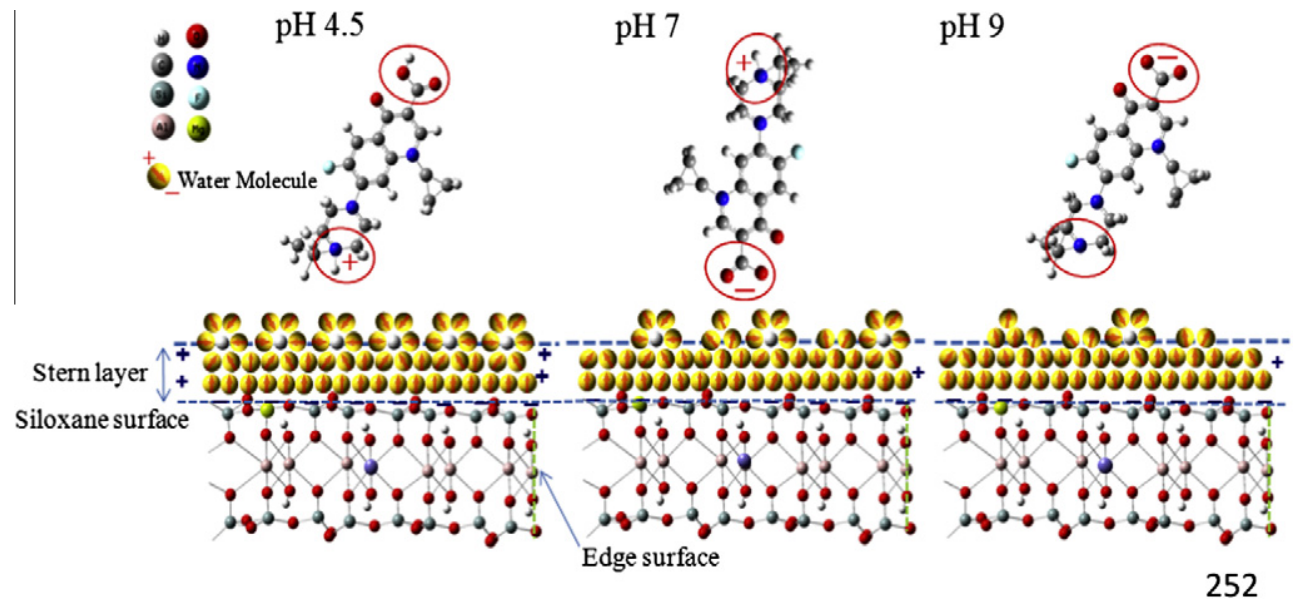

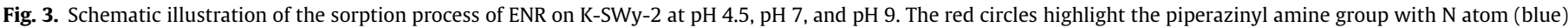
and carboxyl group with $\mathrm{O}$ atom (red). (For interpretation of the references to color in this figure legend, the reader is referred to the web version of this article.)

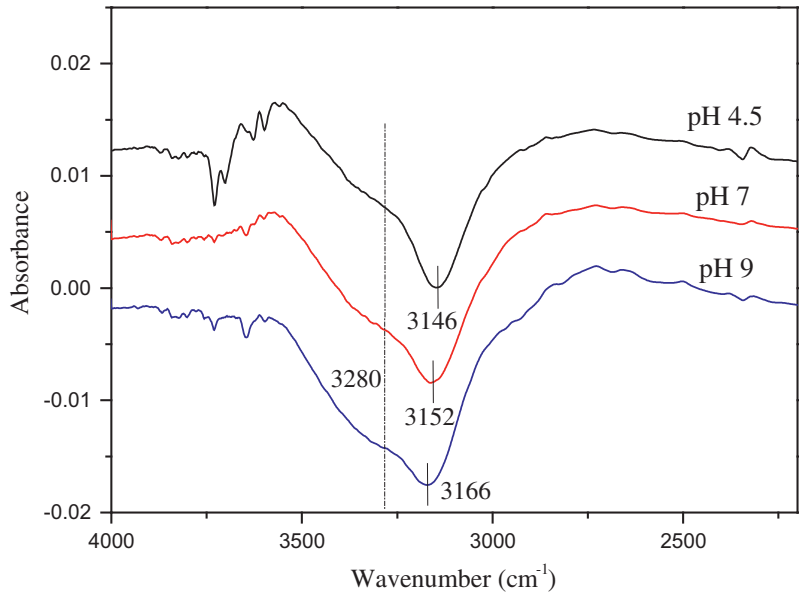

Fig. 4. FTIR spectra of ENR adsorbed on K-SWy-2 in the region of $4000-2200 \mathrm{~cm}^{-1}$ at $\mathrm{pH} 4.5,7$, and 9.

currence of the absorbance loss at 3146 and $3280 \mathrm{~cm}^{-1}$ implied the multiple sorption mechanisms of ENR on the montmorillonite surfaces.

\subsection{FTIR study of DOM sorption on clay film}

Understanding the DOM sorption on montmorillonite is a prerequisite to explore the ENR sorption in the presence of DOM. ATR-FTIR spectra of adsorbed HA and FA on clay are shown as a function of adsorption time in Fig. 5. In the $3600-2800 \mathrm{~cm}^{-1}$ region (Fig. 5b and d), both HA and FA exhibited progressive absorbance loss. For HA, the position of the main negative peak was initially at around $3223 \mathrm{~cm}^{-1}$ and gradually shifted to $3164 \mathrm{~cm}^{-1}$ after $150 \mathrm{~min}$. This absorbance loss was probably due to the release of adsorbed hydrated protons. Besides, the growth of the negative peak at $3223 \mathrm{~cm}^{-1}$ was coincident with the emergence of a negative shoulder peak at around $3340 \mathrm{~cm}^{-1}$, indicating the concurrent removal of surface water. This observation indicated that HA can interact with clay surface through multiple mechanisms because of its diverse functional moieties. In contrast, adsorbed FA only exhibited a broad negative peak around $3332 \mathrm{~cm}^{-1}$ (Fig. 5d). This difference in HA and FA adsorption spectra might be attributed to their different physical conformation, especially the contents of amino groups. HA contains about $2.1 \% \mathrm{~N}$, which was higher than FA $(0.7 \% \mathrm{~N}$ in FA) [37,38].The amino groups in HA could facilitate the release of both hydrated hydrogen protons and water molecules originally adsorbed on the mineral surfaces, while the FA sorption could mainly replace adsorbed water.

The spectrum of HA in the region $1850-650 \mathrm{~cm}^{-1}$ (Fig. 5a) showed the absence of peak at $1720 \mathrm{~cm}^{-1}$, which is probably caused by the ligand exchange between HA carboxyl functional groups and hydroxyl groups on edge surface of clay [22]. The extremely broadened peak at around $1630 \mathrm{~cm}^{-1}$, assigned as $\mathrm{C}=\mathrm{O}$ stretching vibrations, can be attributed to the heterogeneous nature of HA, which has a wide distribution of chemical environments for ketone groups. Compared to the $\mathrm{C}=\mathrm{O}$ stretching vibration, the peak intensity of aromatic $C=C$ stretching at around $1600 \mathrm{~cm}^{-1}$ was relatively weak and in discriminable. A huge negative peak at around $1075 \mathrm{~cm}^{-1}$ could be due to the release of adsorbed carbon- 
ate in the presence of HA [22]. Besides, the relative high content of amino groups in HA exhibited a prominent $\tau_{\mathrm{NH}}$ at $1305 \mathrm{~cm}^{-1}$.

In comparison with adsorbed HA, a similar FTIR spectrum of adsorbed FA in the region $1850-650 \mathrm{~cm}^{-1}$ was obtained except the presence of $\mathrm{C}=\mathrm{O}$ stretching vibrations and relative weak $\tau_{\mathrm{NH}}$ (Fig. 5c). Two peaks at 749 and $835 \mathrm{~cm}^{-1}$ were observed in FA (Fig. 5c) that were assigned to $\mathrm{OH}$ deformation of the non- $\mathrm{H}-$ bonded surface $\mathrm{OH}$ group and the bulk $\mathrm{OH}$ group, respectively [28]. Because these two peaks were unique for FA in our investigated system, they can be used as an index of FA sorption sequence in the following 2D-COS analysis.

\subsection{Bi-solute sorption on clay film}

DOM can greatly affect the sorption of organic compounds on clay minerals. Generally, the influence was explained by the pore blockage and direct site competition. In our previous study [18], however, negligible impact was found at acidic condition in the presence of HA at low concentration $\left(5 \mathrm{mg} \mathrm{L}^{-1}\right)$. One reason for this marginal impact was that the bulky volume of HA molecules $\left(0.43-0.63 \mathrm{~cm}^{-3} \mathrm{~g}^{-1}\right)$ is too large to fit on the nanometer-scale surface charged sites on montmorillonite $(0.26 \mathrm{~nm})$ [18]. Another reason, which may be more important, was that soluble HA and FA are negatively charged in a broad $\mathrm{pH}$ range $\left(\mathrm{pH}_{\mathrm{PZC}}<3\right.$ [39]). The electrostatic repulsion between negative HA/FA and basal plane of montmorillonite weakens their interaction.

In contrast, when the bi-solute sorption experiments were conducted containing ENR (10 $\left.\mathrm{mg} \mathrm{L}^{-1}\right)$ and FA (100 $\left.\mathrm{mg} \mathrm{L}^{-1}\right)$ as co-solutes at $\mathrm{pH} 4.5$, strong affinity between FA and free ENR was found. As shown in Fig. 6a, the peak intensity at $1302 \mathrm{~cm}^{-1}\left(\tau_{\mathrm{NH}}\right)$ and
$1264 \mathrm{~cm}^{-1}\left(v_{\mathrm{COOH}}\right.$ and $\left.\delta_{\mathrm{C}-\mathrm{OH}}\right)$ was increased with time. Moreover, the increase rate at $1302 \mathrm{~cm}^{-1}$ was much slower than that at $1264 \mathrm{~cm}^{-1}$. It was quite different from the IR analysis for singlesolute ENR sorption that these two peaks should increase simultaneously (Fig. 1c). The difference indicated that the piperazinyl amine group of ENR in bi-solute system could interact with soluble FA before the sorption on mineral surface. In addition, in the region $3600-2800 \mathrm{~cm}^{-1}$ at $\mathrm{pH} 4.5$ (Fig. 6b), the position of negative peak was shifted from $3284 \mathrm{~cm}^{-1}$ to $3344 \mathrm{~cm}^{-1}$ with time, which was close to the peak position of single FA sorption $\left(3332 \mathrm{~cm}^{-1}\right.$, Fig. 5d). The negative shoulder peak at $3280 \mathrm{~cm}^{-1}$ (Fig. 4) in the single-solute ENR sorption was also present in bi-solute system with a peak shift to $3220 \mathrm{~cm}^{-1}$ (Fig. 6b). The negative peak at $3148 \mathrm{~cm}^{-1}$ (Fig. 1b), which was attributed to the cation exchange between protonated piperazinyl amine group of ENR and hydrated hydrogen ion, was not observed in bi-solute system. The results also suggested that the piperazinyl amine groups of dissolved ENR interacted with soluble FA under acidic conditions.

Furthermore, consistent results are obtained from the 2D-COS analysis. Based on the signs of synchronous correlation peaks and asynchronous correlation peaks (Fig. 6c, d), the sequence of the spectral change was $-\mathrm{COOH} \rightarrow-\mathrm{NH}^{+} \rightarrow \mathrm{P}_{749} \sim \mathrm{P}_{835}$ (“ $\sim$ ” means simultaneous to, " $\mathrm{P}_{749}$ " and " $\mathrm{P}_{835}$ " are two specific peaks for $\mathrm{FA}$ ). Compared with the sorption consequence of single-solute system, the results of $2 \mathrm{D}$-COS analysis of bi-solute sorption showed that the presence of FA changed the sorption sequence of ENR on montmorillonite surface.

The strong affinity between ENR and FA at pH 4.5 could be explained by several mechanisms. First, electrostatic interaction might be the predominant driving force for this strong interaction.
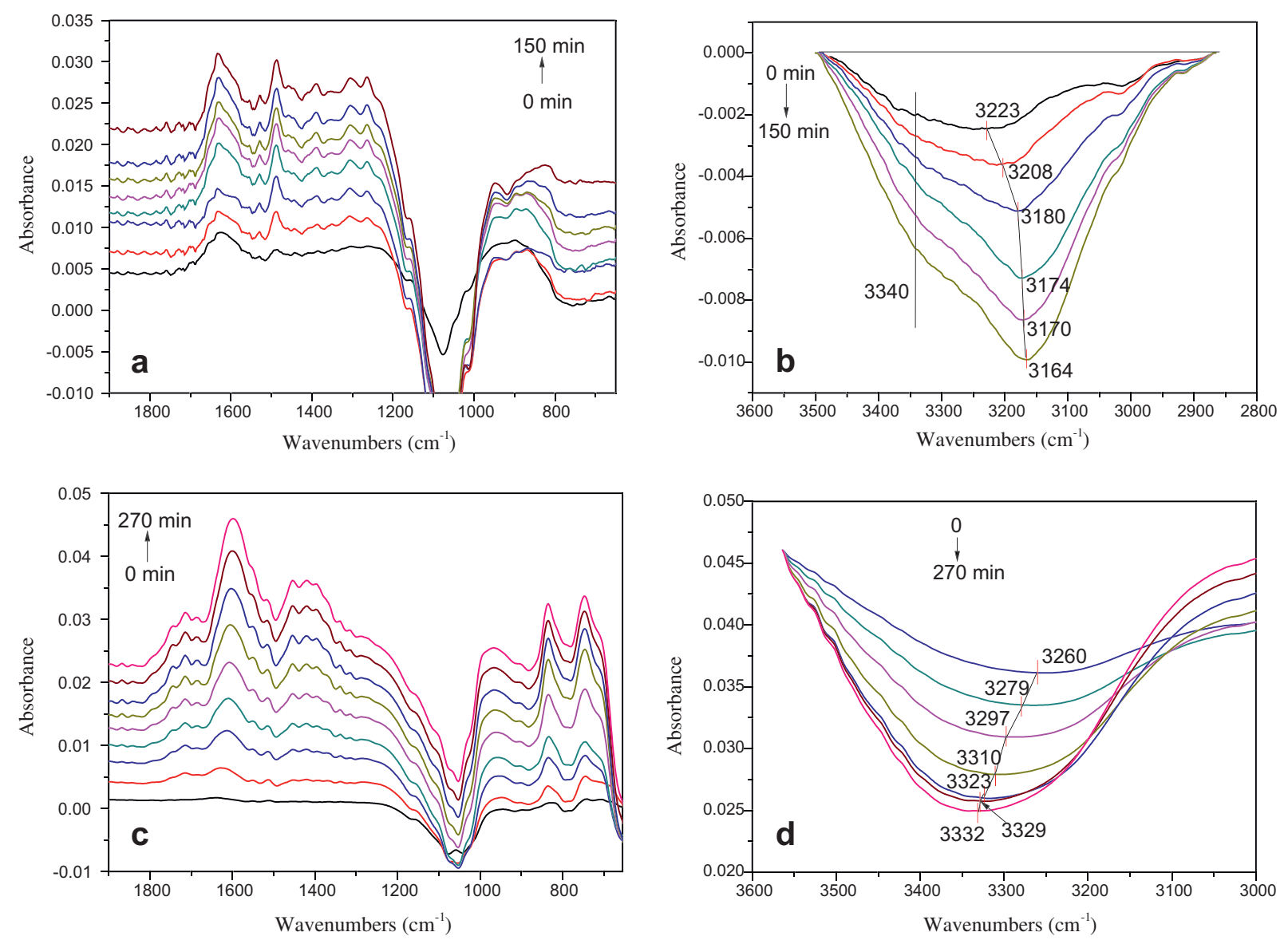

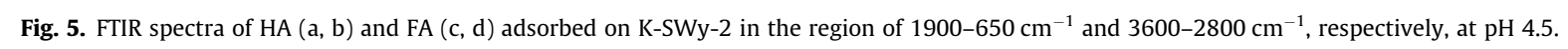



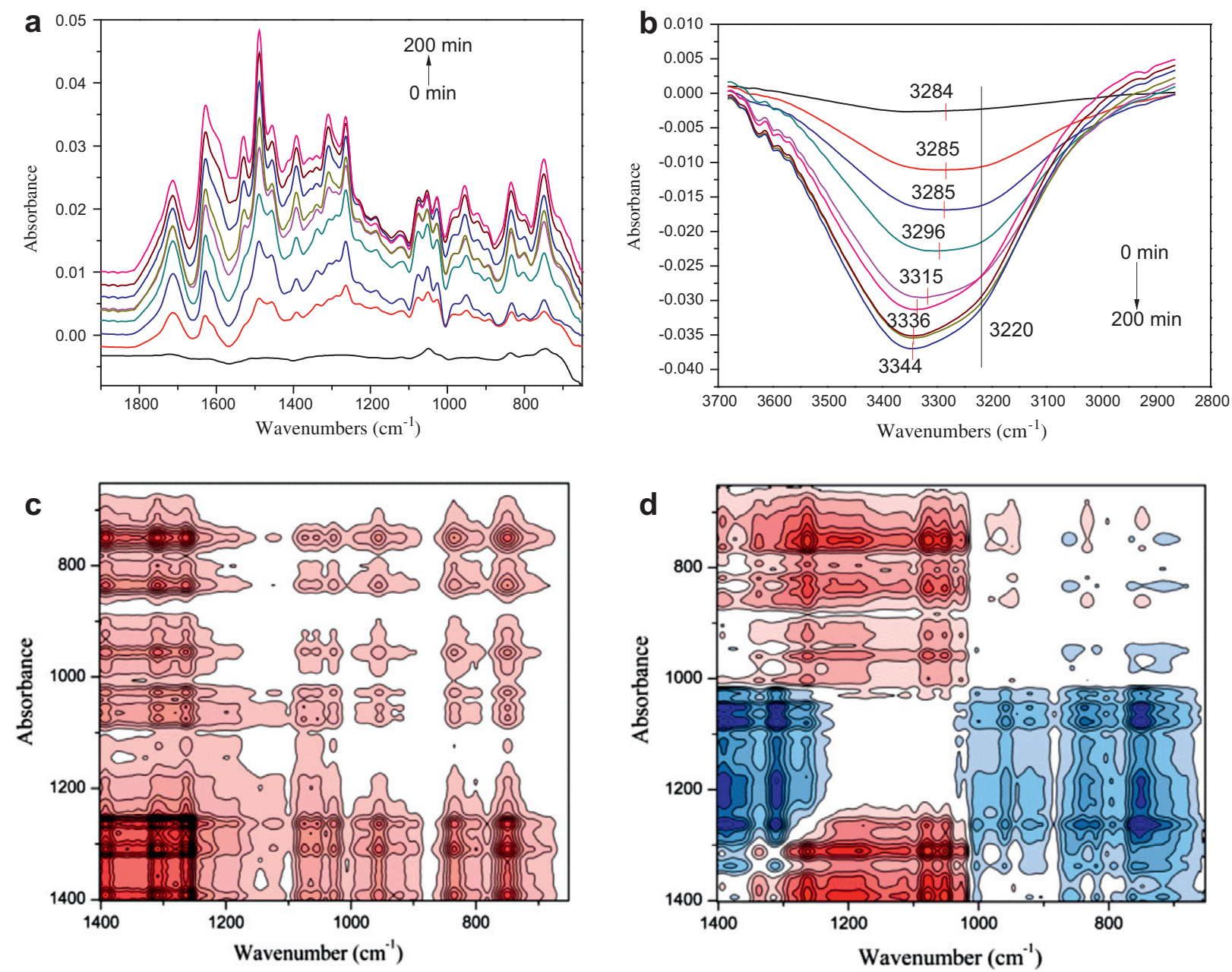

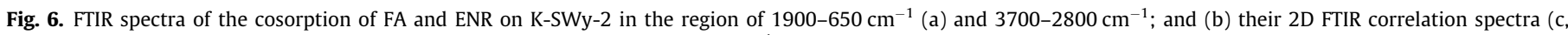
synchronous spectrum; $d$, asynchronous spectrum) in the region of $1400-650 \mathrm{~cm}^{-1}$ at $\mathrm{pH} 4.5$.

At $\mathrm{pH} 4.5, \mathrm{ENR}^{+}$is the dominant species. The positively charged piperazinyl amine groups of $\mathrm{ENR}^{+}$can form strong ionic bonds with carboxylic groups of FA which is the second strongest binding type following covalent bond [19]. Second, H-donor-acceptor interaction could be responsible for this affinity. FA may act as hydrogen-bond donors because of their appreciable amount of carboxylic and phenolic moieties, and $\mathrm{ENR}^{+}$may act as hydrogenbond acceptors by their carbonyl and carboxyl groups [39]. Conversely, the deprotonated carboxyl groups of FA could also act as hydrogen-bond acceptors and form $\mathrm{H}$-bonds with positively charged piperazinyl amine groups of $\mathrm{ENR}^{+}$[19]. Third, the $\pi-\pi$ interaction may also contribute to this affinity. Wang et al. [40] have reported that the norfloxacin, a FQ antibiotic with similar molecular structure to that of ENR, could function as a $\pi$-electron acceptor due to the strong electron withdrawing ability of the fluorine group on benzene ring, whereas benzene ring of carboxylated carbon nanotubes could function as a $\pi$-electron donor. Similarly, this $\pi-\pi$ interaction between benzene ring of ENR and aromatic domain of FA may also exist.

\section{Conclusions}

ATR-FTIR and 2D-COS were used to explore the sorption process of ENR on montmorillonite in this study. The sorption mechanisms depended on $\mathrm{pH}$ : The sorption of ENR at mineral-water interface was predominantly initiated by cation exchange at acidic condition, charge neutralization at neutral condition, and proton transfer at alkaline condition. The different sorption processes were due to various ENR species and surface potentials at different $\mathrm{pH}$. Besides, ligand exchange between hydroxyl groups on the edge surface of montmorillonite and carboxyl groups of ENR would also be responsible for the interaction of ENR with clay. Water molecules at mineral surface can combine with proton to form hydrated hydrogen ions and then play an important role in the proton transfer for the sorption. In addition, the polar functional groups (e.g., $\mathrm{OH},-\mathrm{COOH}$ ) of DOM can interact with piperazinyl amine groups of ENR and subsequently influence the ENR sorption process at interfacial surfaces. The results of this study can improve our understanding of the fate and risk assessment of FQ antibiotics and, more generally, complex environmentally relevant IOCs in soils.

\section{Acknowledgment}

This work is supported by the National Natural Science Foundation of China $(21007080,41023005,20890112)$ and the Youth Fund of State Key Laboratory of Environmental Chemistry and Ecotoxicology QN2009-05.

\section{Appendix A. Supplementary material}

Supplementary data associated with this article can be found, in the online version, at http://dx.doi.org/10.1016/j.jcis.2012.09.039. 


\section{References}

[1] Y. Picó, V. Andreu, Anal. Bioanal. Chem. 387 (2007) 1287.

[2] A. Nowara, J. Burhenne, M. Spiteller, J. Agric. Food Chem. 45 (1997) 1459.

[3] N.M. Vieno, T. Tuhkanen, L. Kronberg, J. Chromatogr. A 1134 (2006) 101.

[4] M. Seifrtova, A. Pena, C.M. Lino, P. Solich, Anal. Bioanal. Chem. 391 (2008) 799.

[5] S. Babic, D.M. Pavlovic, D. Aperger, M. Perisa, M. Zrncic, A.J.M. Horvat, M. Kastelan-Macan, Anal. Bioanal. Chem. 398 (2010) 1185.

[6] P. Trivedi, D. Vasudevan, Environ. Sci. Technol. 41 (2007) 3153.

[7] N. Kemper, Ecol. Indic. 8 (2008) 1.

[8] A. Hartmann, A.C. Alder, T. Koller, R.M. Widmer, Environ. Toxicol. Chem. 17 (1998) 377.

[9] S.A. Boyd, G. Sheng, B.J. Teppen, C.T. Johnston, Environ. Sci. Technol. 35 (2001) 4227.

[10] Z.G. Pei, X.Q. Shan, J.J. Kong, B. Wen, G. Owens, Environ. Sci. Technol. 44 (2010) 915.

[11] C.-J. Wang, Z. Li, W.-T. Jiang, J.-S. Jean, C.-C. Liu, J. Hazard. Mater. 183 (2010) 309.

[12] Q. Wu, Z. Li, H. Hong, K. Yin, L. Tie, Appl. Clay Sci. 50 (2010) 204.

[13] C. Gu, K.G. Karthikeyan, Environ. Sci. Technol. 39 (2005) 9166.

[14] A.A. MacKay, D.E. Seremet, Environ. Sci. Technol. 42 (2008) 8270.

[15] K.W. Goyne, J. Chorover, J.D. Kubicki, A.R. Zimmerman, S.L. Brantley, J. Colloid Interface Sci. 283 (2005) 160.

[16] A.C. Hari, R.A. Paruchuri, D.A. Sabatini, T.C.G. Kibbey, Environ. Sci. Technol. 39 (2005) 2592.

[17] A.J. Carrasquillo, G.L. Bruland, A.A. MacKay, D. Vasudevan, Environ. Sci. Technol. 42 (2008) 7634.

[18] W. Yan, S. Hu, C. Jing, J. Colloid Interface Sci. 372 (2012) 141.
[19] M.K. Richter, M. Sander, M. Krauss, I. Christl, M.G. Dahinden, M.K. Schneider, R.P. Schwarzenbach, Environ. Sci. Technol. 43 (2009) 6632.

[20] K.A. Thorn, P.J. Pettigrew, W.S. Goldenberg, E.J. Weber, Environ. Sci. Technol. 30 (1996) 2764.

[21] S. Kang, B. Xing, Langmuir 24 (2008) 2525

[22] K. Yang, D. Lin, B. Xing, Langmuir 25 (2009) 3571.

[23] I. Noda, J. Am. Chem. Soc. 111 (1989) 8116

[24] I. Noda, J. Mol. Struct. 974 (2010) 3.

[25] B. Rotenberg, V. Marry, N. Malikova, P. Turq, J. Phys.-Condens. Matter 2 (2) (2010) 284114

[26] L.N. Warr, J.N. Perdrial, M.-C. Lett, A. Heinrich-Salmeron, M. Khodja, Appl. Clay Sci. 46 (2009) 337.

[27] Y. Mee Jung, I. Noda, Appl. Spectrosc. Rev. 41 (2006) 515.

[28] S.L. Wang, C.T. Johnston, D.L. Bish, J.L. White, S.L. Hem, J. Colloid Interface Sci. 260 (2003) 26

[29] E.S. Stoyanov, I.V. Stoyanova, C.A. Reed, J. Am. Chem. Soc. 132 (2010) 1484.

[30] H. Ohtaki, T. Radnai, Chem. Rev. 93 (1993) 1157.

[31] G. Sposito, Proc. Natl. Acad. Sci. 96 (1999) 3358.

[32] M.J. Avena, M.M. Mariscal, C.P. De Pauli, Appl. Clay Sci. 24 (2003) 3.

[33] T. Hiemstra, W.H. Van Riemsdijk, J. Colloid Interface Sci. 179 (1996) 488.

[34] M. Duc, F. Gaboriaud, F. Thomas, J. Colloid Interface Sci. 289 (2005) 139.

[35] P. Zarzycki, F. Thomas, J. Colloid Interface Sci. 302 (2006) 547.

[36] S.A. Dickie, A.J. McQuillan, Langmuir 20 (2004) 11630.

[37] T.H. Yoon, S.B. Johnson, G.E. Brown, Langmuir 21 (2005) 5002.

[38] E. Tipping, Cation Binding by Humic Substances, Cambridge Univ. Press, Cambridge, 2004

[39] K. Yang, B. Xing, Environ. Pollut. 157 (2009) 1095.

[40] Z. Wang, X. Yu, B. Pan, B. Xing, Environ. Sci. Technol. 44 (2009) 978 